\title{
Investigación Participativa con Jóvenes con Discapacidad Visual: Cuando los Relatos de Exclusión e Inclusión Salen a la Calle
}

\author{
Participatory Research with Young People with Visual \\ Disabilities: When the Exclusion and Inclusion Stories Take to \\ the Streets
}

\author{
Silvia Sierra Martínez 1* \\ María Fiuza Asorey ${ }^{2}$ \\ Ángeles Parrilla ${ }^{1}$ \\ ${ }^{1}$ Universidade de Vigo, España \\ ${ }^{2}$ Universidade de Santiago de Compostela, España
}

\begin{abstract}
El propósito de este estudio es visibilizar la realidad de personas con discapacidad visual, se lleva a cabo una Biblioteca Humana o Human Library como una estrategia metodológica de carácter innovador y participativo. Participan en la misma un grupo de adolescentes con alguna discapacidad visual, quiénes a través de sus narraciones comparten con distintos agentes sociales sus experiencias y vivencias vinculadas a la discapacidad y la respuesta social a la misma. En este trabajo, se analizan las voces de dos de esos jóvenes que eligen para su relato oral la narración de su trayectoria escolar desde la infancia hasta la enseñanza post-obligatoria. Las estrategias de investigación participativa utilizadas durante la celebración de la Biblioteca Humana, así como los registros de los grupos de discusión previos y la observación participante. El análisis permite identificar las barreras educativas más recurrentes de los jóvenes, relacionadas con el clima de los centros, las metodologías y el papel de los docentes, pero también permite identificar algunas palancas de cambio que invitan a repensar las prácticas educativas de inclusión y exclusión escolar.
\end{abstract}

Descriptores: Investigación participativa; Ceguera; Exclusión social; Educación para todos; Justicia social.

In order to visibilize the reality of people with visual disabilities, a Human Library is carried out as an innovative and participatory methodological strategy. A group of adolescents with some visual disability, participate sharing through their narratives their experiences and experiences related to disability and the social response. In this work, the voices of two teenagers with blindness who choose for their oral story the narration of their school career from childhood to postcompulsory education are analyzed. The participatory research strategies used during the celebration of the Human Library as well as the records of the previous discussion groups and the participant observation. The analysis make possible to identify the more recurrent educational barriers in the history of young people related to the climate of the educational centers, the methodologies and the role of teachers, but also makes possible identify levers of change that invite us to rethink the educational practices of school inclusion and exclusion.

Keywords: Participant research; Blindness; Social exclusion; Universal education; Social justice.

*Contacto: sierra@uvigo.es

ISSN: 2254-3139

www.rinace.net/riejs/

revistas.uam.es/riejs
Recibido: $\quad 2$ de octubre 2019

$1^{\text {a }}$ Evaluación: 21 de noviembre 2019

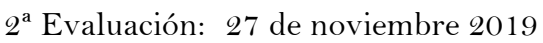

Aceptado: $\quad 12$ de diciembre 2019 


\section{Revisión de la literatura}

El propósito de este artículo es presentar un proyecto de investigación participativa e inclusiva en torno a las barreras y ayudas que encuentran los jóvenes con discapacidad visual en su trayectoria escolar. Así mismo el estudio pretende ayudarnos a reflexionar y compartir algunas imágenes de la situación vivida por los jóvenes en el día a día escolar de forma que puedan inspirar nuestro pensamiento y una actuación más inclusiva al respecto. También pretende abrir más debates y discusiones sobre cómo hacer de las escuelas espacios más inclusivos y democráticos.

La aproximación a una perspectiva investigadora que calificamos como participativa, inclusiva y democrática, es especialmente válida para el fin que pretendemos ya que los enfoques investigadores que se dan cita bajo la llamada investigación participativa, confluyen en el compromiso con el desarrollo de modos de conocer que sean socialmente justos y democráticos. En su conjunto reclaman también una orientación social para la ciencia, que sea capaz de conectar la creación de conocimiento académico con la realidad, con sus múltiples actores y con la diversidad de perspectivas sobre la misma.

Todos estos enfoques reconocen y respetan, diferentes formas de conocer y diferentes poseedores de conocimiento, exigiendo un acercamiento no sólo más participativo, sino también más creativo a los procesos bajo estudio (Nind, 2014). Suponen así incrementar la participación y autonomía de las personas implicadas en los procesos de investigación, no sólo como personas investigadas sino como coinvestigadores, maximizando su participación desde una relación de igualdad, en un proceso investigador que ha de ser claramente dialéctico. La investigación cumple así la función de facilitar que las personas se impliquen en la actividad de concebir y realizar investigación sobre ellas mismas, lo que favorece el empoderamiento y representación de sus experiencias. Esta idea coincide también con el concepto de investigación inclusiva expuesto por Walmsley y Johnson (2003), quienes la describen como aquella que considera a las personas como sujetos de investigación e instigadoras de ideas, diseño de proyectos o analistas de datos. Esta investigación, busca reconocer la voz de grupos marginados o silenciados en los procesos de producción de conocimiento y fomentar su empoderamiento. Por ello se dice de la investigación inclusiva que es una investigación de tipo participativo y emancipatorio.

Este conjunto de asunciones implica un importante cambio de paradigma, cuestionándose el privilegio y la separación del conocimiento experto de aquel otro conocimiento que surge y se recrea en la experiencia, en la práctica. En contraste con las metodologías convencionales, la investigación inclusiva supone la apertura a nuevos modos de hacer investigación, a nuevas estrategias y herramientas accesibles y sensibles a los participantes. Pero no se trata de hablar de otro tipo más de investigación académica, sino de un nuevo espacio, una lente, que cambia tanto la investigación en sí misma, como las identidades de las personas que investigan (que participan en la investigación).

Investigación inclusiva, participativa y democrática se dan pues la mano, compartiendo en última instancia la idea y la esperanza de que la investigación contribuya a la transformación y mejora de la realidad que se estudia. Esto exige la comprensión y asunción de los procesos de cambio como procesos que han de ser compartidos por los implicados, como procesos desarrollados con la complicidad y el aprendizaje mutuo de aquellos a quienes afectan, estando los participantes involucrados en la construcción colectiva del conocimiento, desde una visión de la investigación como un proceso 
participativo, colaborativo y deliberativo (Nind, 2014). Para ello, la investigación se articula en grupos de investigación heterogéneos, con múltiples voces (que incluyen investigadores profesionales y no profesionales), que parten del reconocimiento de la legitimidad, autoridad y complementariedad de sus diferentes participantes (Parrilla et al., 2017). Así mismo la agenda de la investigación a realizar está determinada por los intereses y por las necesidades de los miembros del grupo (Anyon, 2006). La investigación, desde esta perspectiva, pretende abordar problemas y desafíos cotidianos a los que hacen frente los participantes en el estudio. Así mismo los grupos se comprometen a mejorar y transformar las prácticas estudiadas, con énfasis en el desarrollo de investigación e innovación responsables (Ravitch, 2014; Rip, 2016).

Asumiendo estas ideas sobre la investigación, en 2017, se inicia un Proyecto de investigación denominado "Con luz Propia" que pretende dar a conocer la situación con la que se encuentran jóvenes con discapacidad visual en su trayecto de vida, escolar, social, familiar, etc. Se parte para su análisis de la propuesta de Booth y Ainscow (2011), quiénes plantean que el análisis de las causas y formas mediante las cuales se producen situaciones de marginación o exclusión escolar se puede acometer desde el concepto de "barreras para el aprendizaje y la participación”. Situadas en diversos planos o niveles, estas dificultan o inhiben las posibilidades de aprendizaje y participación de quienes han sido a menudo etiquetados como "especiales", impidiendo el desarrollo de una trayectoria educativa o escolar estable y en condiciones de equidad. Por ejemplo, se manifiestan en unos casos dificultando el acceso a la educación y, en otros, limitando su participación y progreso en la misma. Así mismo, como se sabe, las barreras pueden generarse en muy diversos ámbitos: en los centros educativos, en la comunidad, en las políticas locales y en las nacionales. Las barreras son en todo caso construcciones sociales que se manifiestan en forma de actitudes, prácticas sociales, circunstancias materiales, económicas, etc. (Parrilla et al., 2011).

Algunas de estas barreras tienen su origen en la teoría del déficit, según la cual se entiende al alumnado desde la identificación de grupos específicos que justifican el desarrollo de estrategias de compensación centradas en los déficits individuales (Booth, 2011; Muñoz, López y Assaél, 2015). Para Boot (2011) y Booth y Ainscow (2011), tiende a centrarse la mirada en el impedimento o deficiencia de quien ha de ser educado y se resta importancia, o sencillamente se ignoran, factores decisivos en su desarrollo como los planes de estudio del centro escolar, el contenido curricular, los estilos de enseñanza y aprendizaje o las formas en que se evalúa el progreso del alumnado. Como consecuencia, se divide al alumnado según su logro y se le atribuyen etiquetas de capacidad desde los inicios de su escolaridad, lo que suele limitar poderosamente lo que se piensa que podrían alcanzar en el futuro, a la vez que restringe sus propias expectativas. Pero, como señalábamos, el foco de atención debe orientarse más allá del modelo esencialista y centrarse en torno a las circunstancias culturales, sociales, políticas y económicas, y no solo educativas, en las que se producen esos procesos de exclusión y segregación.

Por otro lado, las palancas para el cambio son, siguiendo a Senge (1989), todas aquellas acciones que posibilitan cambios en el comportamiento de una organización y de las personas que la integran. Interesan especialmente aquellas palancas que presentan un mayor "impulso", es decir, las que no están centradas en cambiar el aspecto de las cosas tal y como sucede a menudo en los documentos políticos, normativas o declaraciones, si no que se centran en aspectos que consiguen cambios más reflexivos y significativos (Ainscow, 2004). 
Para Echeita y Ainscow (2011) un factor básico que muestra poseer un gran potencial como palanca de cambio, es la propia forma de conceptualizar la educación inclusiva. Este concepto actúa como palanca cuando es entendido como un proceso, una tarea interminable en la que se buscan formas que respondan a la diversidad de quienes aprenden, y cuando se relaciona con la tarea de identificar y remover barreras, lo que permitirá una mejora en las políticas y en las prácticas educativas. El concepto así definido lleva implícita la presencia, participación y rendimiento de todo el alumnado, prestando especial atención a quienes pueden estar en riesgo de marginación, exclusión o fracaso escolar.

\section{Método}

En este estudio, con la finalidad de desarrollar un proceso de investigación inclusivo orientado hacia el cambio, la sensibilización social y la mejora de los participantes se opta por el desarrollo de una Biblioteca Humana o Human Library (en adelante HL) por su carácter innovador y participativo. Una HL es una "biblioteca” en la que los libros son personas que comparten sus relatos orales con el "lector/a" cuando este acude a la biblioteca. En este caso, los libros, personas con discapacidad visual, se convierten en coinvestigadores de un proceso pensado y articulado para ellos y con ellos a través de la narración de sus historias. Esta metodología permite, a través del diálogo y la reflexión conjunta, crear espacios de compromiso social en los que lo físico pierde valor en detrimento de las emociones, desafiando así estereotipos y prejuicios que la sociedad tiene ante personas con capacidades visuales diversas. Así, el diálogo se convierte en la esencia de las HL: personas que cuentan historias y personas que escuchan esas historias, dando la oportunidad a todos los participantes de reformular situaciones, problemas y vivencias, permitiendo construir conjuntamente, lo que Booth (1998) califica como "narraciones que rompen moldes".

El proceso de investigación desarrollado en torno a la HL, ha sido en el marco del Proyecto "Redes de Innovación para la Inclusión Educativa y Social” (MINECO-EDU2015-68617-C4$\left.1-\mathrm{R}^{1}\right)$. Se plantea desde su inicio 3 objetivos prioritarios: promover el diálogo y el encuentro entre personas que normalmente no tendrían la oportunidad de interactuar; dar voz a personas que han sufrido situaciones de exclusión social por tener discapacidad visual; y sensibilizar sobre la importancia de la inclusión, la justicia social y la igualdad de oportunidades.

“Con Luz Propia”, el nombre otorgado a la HL, une a un grupo heterogéneo de trabajo conformado por personas afiliadas a la Organización Nacional de Ciegos Españoles (ONCE) y a investigadoras de la Universidad de Vigo. La cooperación establecida entre ambas entidades enriquece el proceso de investigación a la vez que le otorga un carácter identitario y diferenciador. Los co-investigadores en este estudio son los relatores o "libros humanos" de la HL, 11 adolescentes de edades comprendidas entre los 12 y los 25 años que tienen en común sus diferentes capacidades visuales, 1 familia con una hija con discapacidad visual y 2 maestras (una invidente y otra vidente) vinculadas profesionalmente a este colectivo. Cuentan durante todo el proceso con el apoyo de la pedagoga del Centro de Recursos Educativos (CRE) de la ONCE en Pontevedra (Galicia,

\footnotetext{
${ }^{1}$ Dirigido por Prof. Ángeles Parrilla de la Universidad de Vigo.
} 
España) y con 9 miembros del equipo de investigación externo de la Universidad de Vigo (3 investigadoras y 6 alumnas voluntarias del Grado de Maestro/a de Educación Infantil).

El proceso de trabajo desarrollado, tiene una duración de un curso académico (2017-2018), se articula en 3 etapas diferenciadas que se retroalimentan mutuamente, dando lugar a un proceso vivo, en constante desarrollo. Tras la primera toma de contacto entre participantes de la ONCE y de la Universidad, tiene lugar la primera etapa de formación. En dos sesiones instructivas, relatores e investigadoras externas hacen un acercamiento pedagógico a la metodología de HL, así como una aproximación didáctica a la investigación participativa y a los relatos narrativos.

A continuación, en una segunda etapa compuesta por tres sesiones de trabajo, los relatores desarrollan un proceso individual e introspectivo en el que identifican las barreras que se han encontrado a lo largo de su vida por tener discapacidad visual y las palancas de cambio que han favorecido su inclusión en la sociedad. Durante este proceso de introspección, de "mirar" respetuosamente hacia su interior, de reflexionar y conectar consigo mismos, diseñan la estructura narrativa de su relato oral y toman decisiones en cuanto al contenido del mismo (“¿qué quiero contar como libro humano?, ¿qué aspectos o experiencias de mi vida personal no quiero compartir?").

Cuadro 1. Libros humanos individuales participantes en la HL (1 relator)

\begin{tabular}{|c|c|c|}
\hline $\begin{array}{l}\text { DESCRIPCIÓN DEL } \\
\text { RELATOR }\end{array}$ & $\begin{array}{l}\text { ESTRUCTURA NARRATIVA DEL } \\
\text { RELATO ORAL Y METODOLOGÍA }\end{array}$ & MENSAJE PRINCIPAL \\
\hline $\begin{array}{l}\text { Adolescente de } \\
\text { nacionalidad extranjera } \\
\text { con restos visuales }\end{array}$ & $\begin{array}{l}\text { Libro de vida: elaboración de un } \\
\text { relato autobiográfico sobre su } \\
\text { trayectoria familiar }\end{array}$ & $\begin{array}{l}\text { “Por qué no me crees? Os voy a } \\
\text { contar por qué no me creían } \\
\text { que no veía bien cuando llegue } \\
\text { a España” }\end{array}$ \\
\hline $\begin{array}{l}\text { Adolescente en edad } \\
\text { universitaria con ceguera }\end{array}$ & $\begin{array}{l}\text { Anecdotario: recopilación de } \\
\text { incidentes críticos ocurridos } \\
\text { durante su trayectoria } \\
\text { universitaria } \\
\end{array}$ & $\begin{array}{l}\text { "Descubrí un nuevo mundo } \\
\text { desde que llegué a nueva } \\
\text { ciudad llena de } \\
\text { oportunidades" }\end{array}$ \\
\hline $\begin{array}{l}\text { Adolescente con doble } \\
\text { discapacidad: visual } \\
\text { (restos visuales) y } \\
\text { motórica. }\end{array}$ & $\begin{array}{l}\text { Anecdotario: recopilación de } \\
\text { incidentes críticos ocurridos } \\
\text { durante su trayectoria escolar }\end{array}$ & $\begin{array}{l}\text { "Quiero ser como los demás y } \\
\text { hacer las mismas cosas o, por } \\
\text { lo menos, intentarlo" }\end{array}$ \\
\hline $\begin{array}{l}\text { Adolescente deportista con } \\
\text { ceguera }\end{array}$ & $\begin{array}{l}\text { Viaje: narración de su relación } \\
\text { con el deporte hacia una meta } \\
\text { futura, poder competir a nivel } \\
\text { profesional }\end{array}$ & $\begin{array}{l}\text { "Digo lo que pienso cuando } \\
\text { quiero y no dejo pasar } \\
\text { fácilmente las afrentas" }\end{array}$ \\
\hline $\begin{array}{l}\text { Adolescente amante de la } \\
\text { lectura con restos } \\
\text { visuales }\end{array}$ & $\begin{array}{l}\text { Viaje: narración de su relación } \\
\text { con la lectura hacia una meta } \\
\text { futura, poder leer en ambos } \\
\text { formatos }\end{array}$ & $\begin{array}{l}\text { "Entre dos aguas: entre el } \\
\text { braille y la lectura en tinta" }\end{array}$ \\
\hline $\begin{array}{l}\text { Adolescente con ceguera } \\
\text { total desde el nacimiento }\end{array}$ & $\begin{array}{l}\text { Libro de vida: elaboración de un } \\
\text { relato autobiográfico sobre su } \\
\text { trayectoria escolar }\end{array}$ & "La escuela a oscuras" \\
\hline $\begin{array}{l}\text { Maestra ciega en el CRE de } \\
\text { Pontevedra de alumnado } \\
\text { adulto }\end{array}$ & $\begin{array}{l}\text { Libro de vida: elaboración de un } \\
\text { relato autobiográfico sobre su } \\
\text { trayectoria personal y laboral }\end{array}$ & $\begin{array}{l}\text { "Enseño braille a personas } \\
\text { adultas que han perdido la } \\
\text { visión" }\end{array}$ \\
\hline $\begin{array}{l}\text { Maestra en un centro } \\
\text { público de Educación } \\
\text { Infantil de un nuevo } \\
\text { alumno con ceguera }\end{array}$ & $\begin{array}{l}\text { Cuento clásico: estructuración en } \\
\text { inicio, nudo, desenlace y } \\
\text { moraleja de su experiencia en } \\
\text { un nuevo reto profesional }\end{array}$ & $\begin{array}{l}\text { "Siempre aprendo más de lo que } \\
\text { enseño..." }\end{array}$ \\
\hline
\end{tabular}


Como resultado del trabajo realizado los relatores construyen un borrador de su relato oral, un discurso propio, singular, que les permite conocerse y darse a conocer, estando en todo momento acompañados por la pedagoga del CRE y las investigadoras de la Universidad. Dada la libertad metodológica que cada participante tiene durante esta fase de trabajo personal, unos optan por redactar dicho borrador, otros prefieren elaborar notas informales e, incluso, algunos graban notas de voz personales en las que registran aquello que quieren compartir con el público.

Cuando cada relator tiene definido un primer borrador de su relato oral, en la tercera etapa de la investigación, se desarrollan dos sesiones más en las que se combina la metodología de trabajo en pequeños grupos con un grupo de discusión en el que se dan y reciben apoyo mutuo y ponen en común sus decisiones personales relativas a su discurso. Conscientes de que la afluencia de público, cuando se celebre la HL, determinará el número de veces que cada relator repetirá su relato oral, aprovechan también estas sesiones de trabajo para ensayar sabiendo que in situ su relato oral va a evolucionar de forma natural producto de una situación espontánea y de la interacción con el público asistente a la HL.

En las siguientes tablas se recogen los 11 libros humanos ( 8 individuales y 3 colectivos) que forman parte de la HL, incluyendo una breve descripción de cada relator, la estructura narrativa de su relato oral, la metodología personal de trabajo de cada participante y el mensaje principal que quiere transmitir.

Cuadro 2. Libros humanos colectivos participantes en la HL (2 relatores)

\begin{tabular}{ccc}
\hline $\begin{array}{c}\text { DESCRIPCIÓN DE } \\
\text { LOS RELATORES }\end{array}$ & $\begin{array}{c}\text { ESTRUCTURA NARRATIVA DEL } \\
\text { RELATO ORAL Y METODOLOGÍA }\end{array}$ & MENSAJE PRINCIPAL \\
\hline $\begin{array}{c}\text { Pareja conformada } \\
\text { por un invidente } \\
\text { y una vidente }\end{array}$ & $\begin{array}{c}\text { Anecdotario: recopilación de incidentes } \\
\text { críticos ocurridos durante su } \\
\text { trayectoria sentimental }\end{array}$ & $\begin{array}{c}\text { "Contaremos nuestra historia de } \\
\text { pareja y cómo la ceguera de él } \\
\text { influyó en ella". }\end{array}$ \\
\hline $\begin{array}{c}\text { Familia (padre y } \\
\text { madre) de una } \\
\text { niña con ceguera }\end{array}$ & $\begin{array}{c}\text { Anétotario: recopilación de incidentes } \\
\text { más próximo y con las relaciones más } \\
\text { influyentes en su hija con ceguera }\end{array}$ & $\begin{array}{c}\text { Defpertando conciencias. } \\
\text { Defenos la inclusión" }\end{array}$ \\
\hline $\begin{array}{c}\text { Pareja con } \\
\text { discapacidad } \\
\text { visual }\end{array}$ & $\begin{array}{c}\text { Anecdotario: recopilación de incidentes } \\
\text { críticos ocurridos durante su } \\
\text { trayectoria universitaria }\end{array}$ & $\begin{array}{c}\text { Ambos coincidimos en señalar } \\
\text { similares fortalezas y } \\
\text { debilidades a lo largo de } \\
\text { nuestra trayectoria } \\
\text { universitaria" }\end{array}$ \\
\hline
\end{tabular}

Fuente: Elaboración propia.

Por último, en la tercera etapa, se celebra la HL "Con Luz Propia”2 como un encuentro al que se invita voluntariamente a participar a toda la comunidad. Simulando una biblioteca, el público que accede a la misma elige libremente un libro humano para leer. Durante 20 minutos escucha la historia, el relato oral del "libro" y, al final, tiene lugar un turno de diálogo en el que los oyentes también interactúan con los relatores y conversan sobre las vivencias relatadas para conocer más de cerca su historia e imaginar cómo ha sido su vida. Al finalizar la ronda, se vuelve a iniciar el proceso. En el caso concreto de nuestro estudio cada relator hace finalmente cuatro rondas.

\footnotetext{
${ }^{2}$ Se puede ampliar la información de esta etapa en Sierra Martínez, Fiuza Asorey y Parrilla (2019).
} 
Cuadro 3. Instrumentos y estrategias de investigación

\begin{tabular}{|c|c|c|c|c|}
\hline & & ESTRATEGIAS & DESCRIPCIÓN & DATOS PRODUCIDOS \\
\hline \multirow{10}{*}{ Primarias } & \multirow{6}{*}{ Previas } & $\begin{array}{l}\text { Conversación reflexiva: personal e } \\
\text { introspectiva }\end{array}$ & $\begin{array}{l}\text { Preguntas-guía abiertas a las que los propios relatores dan } \\
\text { respuesta con un fin exploratorio }\end{array}$ & $\begin{array}{l}\text { 4. horas de grabaciones en audio y en } \\
\text { video }\end{array}$ \\
\hline & & \multirow[b]{2}{*}{ Escritura reflexiva individual } & \multirow{2}{*}{$\begin{array}{l}\text { Elaboración de cuentos, anecdotarios, libros de vida... en } \\
\text { función del relator y en aquellos casos que decidieron optar } \\
\text { voluntariamente por esta metodología }\end{array}$} & 5 relatos escritos \\
\hline & & & & 4 notas informales \\
\hline & & Trabajo en pequeños grupos & Encuentros en grupos de 3 relatores & $\begin{array}{l}\text { 4. horas de grabaciones en audio y en } \\
\text { video }\end{array}$ \\
\hline & & Grupo de discusión & Encuentro entre todos los relatores para recibir apoyo mutuo & $\begin{array}{l}3 \text { horas de grabaciones en audio y en } \\
\text { video }\end{array}$ \\
\hline & & Observación participante & Observación, participación e interacción con los relatores & 9 observaciones \\
\hline & \multirow{2}{*}{ Durante } & $\begin{array}{l}\text { Relatos orales y diálogo } \\
\text { (lectura de libros) }\end{array}$ & Encuentro entre relatores y participantes & $\begin{array}{l}22 \text { horas de grabaciones en audio y en } \\
\text { video }\end{array}$ \\
\hline & & Observación participante & $\begin{array}{l}\text { Observación, participación e interacción con los relatores y los } \\
\text { asistentes a la HL }\end{array}$ & 11 observaciones \\
\hline & \multirow[t]{2}{*}{ Posteriores } & $\begin{array}{l}\text { Cuestionarios escritos de preguntas } \\
\text { abiertas }\end{array}$ & $\begin{array}{l}\text { Valoración de la actividad adaptada a cada perfil de } \\
\text { participante: relatores, familias de los relatores, público en } \\
\text { general e investigadoras de la universidad. }\end{array}$ & 12 cuestionarios \\
\hline & & Panel mudo & 1 panel mudo de impresiones con tres frases incompletas & 45 valoraciones \\
\hline Secundarias & \multicolumn{4}{|c|}{$\begin{array}{l}10 \text { actas de sesiones de trabajo, } 285 \text { fotografías, } 1 \text { video promocional del evento, } 1 \text { rueda de prensa, } 5 \text { noticias en la prensa escrita, cartelería (3 paneles } \\
\text { informativos y } 11 \text { paneles personales), } 1 \text { tríptico del evento y } 1 \text { libro de firmas. }\end{array}$} \\
\hline
\end{tabular}


Para la producción y el registro de información se utilizan instrumentos de investigación participativos (cuadro 3) que destacan por su versatilidad, su capacidad de adaptación a los co-investigadores y a los diferentes momentos del proceso. Por ejemplo, antes de la celebración de la HL, se seleccionan estrategias que facilitan el trabajo introspectivo, como la conversación reflexiva, la escritura reflexiva individual (en aquellos casos en los que los relatores deciden voluntariamente escribir un borrador de su relato oral), y los grupos de discusión entre relatores mientras preparan sus relatos/libros. Durante la celebración de la HL se registran en audio y video las distintas secuencias en las que los participantes narran su historia ante los asistentes (relatos orales y diálogos). Después de la celebración se procede a la valoración de la misma a través de cuestionarios y frases inacabadas (panel mudo). A los mencionados instrumentos, se unen datos secundarios derivados de estrategias como las actas de las sesiones de trabajo, notas de campo, notas de voz, fotografías, grabaciones de video y audio y sus correspondientes transcripciones, notas de prensa, etc.

El proceso de análisis de datos desarrollado se fundamenta en los principios del análisis cualitativo con ayuda del programa MaxQda. Por un lado, se analiza el desarrollo metodológico de cada relato oral a través de 4 categorías: contextualización (objetivo, idea principal que se pretende transmitir e historia personal del relator); proceso de elaboración del relato oral (estructura narrativa, metodología utilizada por cada relator y ritmo narrativo); evolución natural del relato (crecimiento del discurso desde su esbozo hasta la versión final producto de la exposición reiterada y del diálogo con los asistentes a la HL) y dimensión valorativa de relatores y oyentes (impresiones, dificultades encontradas y/o aspectos a mejorar).

Por otro lado, se realiza un segundo análisis sobre el contenido de todos los relatos así como de los diálogos resultantes del encuentro entre relatores y oyentes, aplicando un triple proceso de categorización: codificación de colectivos (clasificación deductiva en función del relator); codificación cronológica (clasificación deductiva en función del momento: si el relator está en la etapa previa a la HL de trabajo introspectivo o en durante la HL con la exposición de su relato oral, a su vez, esta última etapa se clasifica en función del número de ronda) y codificación temática (clasificación inductiva en códigos y categorías de las reflexiones de los relatores y los oyentes/lectores).

Este artículo se centra en el análisis cualitativo de las voces de dos de los jóvenes participantes en HL, ambos con ceguera. Son los dos casos únicos, que narran su trayectoria escolar desde la infancia hasta la enseñanza post-obligatoria (bachillerato). En el siguiente apartado se presentan los resultados de estos dos casos, presentando, en primer lugar, el análisis del proceso metodológico de construcción de los relatos y, en segundo lugar, como resultado del análisis temático, las barreras a la inclusión y las palancas de cambio identificada por las 2 voces a lo largo de su trayectoria educativa. Cabe destacar que ambos relatos son el resultado de la etapa de exposición, es decir, son la versión resultante de la interacción con el público asistente en las últimas rondas de la HL.

\section{Resultados}

\section{1. Análisis del desarrollo metodológico de los relatos}

El libro titulado "La escuela a oscuras" es el relato de un adolescente con ceguera total desde su nacimiento, al que le interesan especialmente las nuevas tecnologías accesibles. 
Cuadro 4. Análisis de contenido del relato "La escuela a oscuras".

\section{ETAPA DE EDUCACIÓN INFANTIL}

Barreras: Primera escolarización y dificultades por parte del centro educativo ante el alumno con discapacidad visual, "hay que valorar obviamente la disposición que tenga cada colegio a tener alumnos ciegos, porque deben estar dispuestos y hacer las adaptaciones que se pidan pero hay colegios inaccesibles...”.

Palancas: Orientación y asesoramiento especializado en el aula por parte de la ONCE, "te asigna un maestro que es el que desde los primeros años de infantil pues va varios días a la semana al aula, te visita y te enseña...”.

Palancas: Aprendizaje del sistema braille en el aula ordinaria, "nos enseña braille con mucha dedicación siempre, porque no es un lenguaje complicado, pero bueno, a los tres años pues sí que sí que tiene su aquel”.

\section{ETAPA DE EDUCACIÓN PRIMARIA}

Palancas: Apoyo del proceso de enseñanza-aprendizaje con recursos TIC y tiflotecnología adaptada al área de conocimiento en el que se van a emplear, "tenía un portátil, una tableta digitalizadora, un bolígrafo señalador... y un día a la semana el profesor de la ONCE nos enseñaba a utilizarlos".

Barreras actitudinales en el centro escolar y reticencia a asumir responsabilidades derivadas de la escolarización del alumnado con discapacidad visual: "el colegio no se quería hacer cargo de comprar un equipo informático adaptado y hacerse cargo del mantenimiento del material y eso que recibían una ayuda pública para comprarlo".

Barreras: Estereotipos, prejuicios y discriminación por parte de otros iguales, "en el patio esperabas a que tocara el timbre, nada es de color de rosa en la vida de nadie...”.

\section{ETAPA DE EDUCACIÓN SECUNDARIA OBLIGATORIA}

Barreras de acceso y admisión en el centro educativo: "al final elegimos centro en función de las personas, no de la titularidad del centro; tenemos que elegir basándonos en la actitud y en la accesibilidad del profesorado".

Barreras actitudinales del profesorado: "hay profesores que incluso se muestran reacios y su comportamiento en la clase es muy importante, es quien te puede ayudar, incluso pedir cosas para nosotros. Y después está la rotación del profesorado, los interinos, hay que enseñarles todo de nuevo".

Palancas: Formación y asesoramiento especializado a los docentes por parte de la ONCE, "la técnica de movilidad enseña a todos los profesores, les da unas pautas sobre cómo transmitir la información y hacerla accesible, aclaran súper dudas que tienen”.

\section{ETAPA DE BACHILLERATO}

Barreras de acceso y admisión en el centro educativo: "a la hora de cambiar a bachiller tuve que hacer otra ronda de institutos pues ver cuál era el que más disposición tenía, algunos se mostraron reacios, otros dubitativos...".

Barreras: Limitaciones técnicas de herramientas de tiflotecnología, "todavía no se pueden leer imágenes, algunas páginas web no están bien hechas, el volumen del material en braille, el peso y el ruido de la máquina Perkins... el acceso a la información todavía no es pleno, nos queda un camino por recorrer"

Barreras: Desaparece la orientación y el asesoramiento especializado en el aula por parte de la ONCE, "en mi caso me la quitaron porque saco buenas notas y consideraron que no era ya necesario que tuviese una asistencia en el aula; en algunos casos acertarán, en otros se equivocarán".

Fuente: Elaboración propia.

En este caso, el autor sigue la estructura narrativa de un libro de vida. Esto significa que plantea una narración cronológica a lo largo de su trayectoria educativa desde educación infantil hasta bachillerato. La estructura elegida para dar forma a su relato le aporta un ritmo narrativo caracterizado por una temporalización lineal, es decir, existe una coincidencia plena entre el orden cronológico propio de la historia y el orden textual del tiempo del discurso. En cuanto a su contenido, el participante elabora su relato autobiográfico sobre su trayectoria educativa, siguiendo su línea de vida y seleccionando momentos vitales de su biografía escolar. 
El autor del libro titulado "Creciendo diferente" es un adolescente con doble discapacidad visual y motórica que quiere transmitir a lo largo de su relato su ansia de "querer ser como los demás”. La estructura narrativa elegida en este caso es un anecdotario en el que recopila incidentes críticos que tuvieron lugar a lo largo de su trayectoria académica desde educación infantil hasta la formación profesional. El participante opta por seguir un ritmo y una temporalización anacrónica, es decir, no existe concordancia entre el orden cronológico de los hechos que conforman la historia y el orden en que son contados en el discurso, sucediéndose continuamente saltos desde el relato presente hacia el pasado. La metodología elegida en este caso es la recopilación y selección de incidentes críticos emocionalmente desestabilizadores que sucedieron a lo largo de su trayectoria académica.

\subsection{Análisis del contenido de los relatos}

En la siguiente tabla se recogen las barreras y palancas identificadas por el primero de los participantes en su relato oral "La escuela a oscuras". Destacan especialmente tres grandes barreras a lo largo de toda su trayectoria, las dificultades puestas por parte de los centros educativos para evitar su escolarización, especialmente en la etapa de educación infantil, la negativa del profesorado a ofrecerle una enseñanza adaptada a sus necesidades o los prejuicios que se repiten a lo largo de su vida escolar. Aunque identifica más barreras que ayudas, también existen en su relato palancas de cambio como la ayuda recibida por instituciones de apoyo a personas con discapacidad visual y el aprendizaje del sistema braille en un entorno de aprendizaje ordinario.

Al igual que en el caso anterior, se recoge a continuación (cuadro 5) el análisis del relato oral "Creciendo diferente" pero en este relato el hilo conductor del análisis de contenido se vertebra en torno a los incidentes críticos identificados por el participante. Fundamentalmente se trata de hechos o situaciones negativas que marcaron un punto de inflexión en su trayectoria académica con el profesorado y en el centro escolar como situaciones de discriminación y estereotipos por su discapacidad visual, así como actitudes negativas y segregadoras que limitan la inclusión académica del protagonista del relato. Destacan también incidentes críticos con otros iguales, por ejemplo, algunas de las situaciones narradas están acompañadas de violencia y acoso, pero también las hay con las familias del resto de compañeros.

\subsection{Análisis comparativo de los relatos}

Ambos relatores coinciden al afirmar categóricamente que, a lo largo de su trayectoria educativa, han estado en contacto con diferentes agentes externos que han jugado un papel fundamental al actuar como facilitadores, en escasas ocasiones, y obstaculizadores, la gran mayoría de las veces, de su proceso de inclusión. En su discurso se evidencia el enorme impacto y la gran influencia que pueden llegar a alcanzar personas ajenas a su entorno más cercano como los docentes, los orientadores escolares de los centros, el resto de iguales o los padres de otros niños/as.

Especial consideración merecen los docentes de las diferentes etapas educativas. Pese a que ambos jóvenes reconocen haber recibido apoyo por parte de los maestros de educación infantil y primaria, en sus relatos prevalecen las dificultades percibidas en las etapas de educación secundaria obligatoria y bachillerato. 
Cuadro 5. Análisis de contenido del relato "Creciendo diferente"

\section{INCIDENTES CRÍTICOS CON EL PROFESORADO}

Estereotipos y prejuicios: "es que tú con las dificultades que tienes ni siquiera deberías de estar haciendo la ESO, deberías de estar haciendo algo especial”.

Discriminación e injusticias: "hay discriminaciones continuamente. A mí me han llegado a decir que era imposible que yo hubiera hecho eso solo, que eso no estaba hecho por mí, y por tanto te tiran para abajo".

Barreras actitudinales del profesorado: "no se quiere, resulta que da trabajo y no interesa, lo de siempre, el trabajar un poco más para que una persona aprenda, no interesa o no debe de interesar. Te dicen "tú no te puedes inscribir a esto porque tienes una discapacidad, este centro no está preparado para ti”.

Especial falta de consideración ante el alumnado con discapacidad visual en el profesorado de ESO: "hay mucha diferencia, el de primaria es vocacional. Mucho peor el de la ESO, lo único que quieren es cobrar".

\section{INCIDENTES CRÍTICOS EN EL CENTRO ESCOLAR}

Barreras arquitectónicas y organizativas en el centro escolar: "muchos centros están muy mal. Hay centros de la ESO que son inaccesibles completamente. Escalones, no hay ascensores, ponen macetas en las escaleras sin avisar, se sientan el resto de compañeros y tropiezas...".

Ausencia de un compromiso pedagógico de escolarización en el centro ordinario: "algún profesor a final de curso me ha aceptado que tenía compañeros que les da todo igual por el simple hecho de que, si yo me iba del centro, mejor para ellos, que tenían menos trabajo para hacer".

\section{INCIDENTES CRÍTICOS CON OTROS IGUALES Y CON SUS FAMILIAS}

Acoso por parte de otros iguales: “empiezan las bromitas, amenazas, papelitos, insultos... situaciones muy complicadas que al final dices... ¿y se supone que yo aquí vengo a aprender y a pasarlo bien?, ¿o vengo a pasarlo mal?, es así, por desgracia es así...”.

Maltrato por parte de los compañeros: "ves que la gente crece, que tus compañeros crecen, y que cuanto más crecen peor es. A mí me han llegado a intentar pegar en la salida del instituto por ser minusválido, sin más. Pues como soy diferente, soy el tonto, pues vamos a por el tonto”.

Repercusión de la actitud de otras familias en las relaciones sociales: "los padres se toman mal que estés con sus hijos. Los niños sin embargo son niños, y les da igual. Y ahí empiezas a ver, por desgracia demasiado pronto, que eres diferente y que a pesar de que tus compañeros de clase, con seis años, cinco años te tratan como a cualquiera, los padres los apartan de ti”.

La tolerancia a la diversidad en las relaciones sociales requiere un proceso de aprendizaje desde la primera infancia: " hoy en día es que no sabemos hablar con nuestra familia, los padres no saben hablar con los niños, no los educan para respetar la diferencia. La gente, la gente es tremenda, pero porque los padres tienen hijos por tener hijos, pero no los educan."

Fuente: Elaboración propia.

En ambos casos ellos destacan, con gran dureza, la actitud negativa del profesorado y sus posturas poco pedagógicas, la poca voluntad de acoger y ayudar a alumnos diversos en su aula, el escaso interés por la aplicación de medidas de atención a la diversidad e, incluso, el bajo nivel de apertura y tolerancia ante el alumnado con discapacidad visual. Es muy ilustrativo sobre esto un fragmento del relato de uno de estos jóvenes que refleja la principal barrera escolar que ellos han encontrado por su discapacidad visual: la conducta de una parte del profesorado y su respuesta negativa ante la atención de la diversidad del alumnado.

Vas a orientación y te dicen: "no, es que tú con las dificultades que tienes ni siquiera deberías de estar haciendo la ESO, deberías estar haciendo algo especial o en algún colegio especial", o "la ONCE debería de darte algo especial para que te eduquen". Pero ¿por qué? les digo, y me dicen "porque eres especial y no puedes seguir las clases y las retrasas". ¿Perdona? "sí, sí, es que tu como no ves retrasas a los alumnos y a tus compañeros, y eso no es justo", pero ¿̈por qué no es justo?, "no, porque hay que hacerte cosas diferentes." Bueno, y yo pienso, ¿estoy aquí para aprender o estoy aquí para hacer la vida más fácil a un profesor? "No, pero es que eres diferente, es que no te mueves bien, es que cómo vas a hacer gimnasia que no puedes, cómo vas a hacer dibujo que no puedes, cómo vas a leer los libros de clase que no puedes... .. Pero vamos a ver, yo aquí 
a que vengo, ¿̇a pasarlo mal?, "no, es que tú deberías de estar en un centro especial que te ayude. (Del libro "Creciendo diferente")

En muchos casos, estas posturas tienen efectos negativos en su relación con el resto de compañeros y los relatores asumen que los docentes mantienen la misma actitud ante conflictos sociales con otros iguales, también en aquellas situaciones con evidencias de maltrato y acoso escolar.

La falta de formación en torno a la discapacidad visual y la falta de capacitación de los docentes para hacer accesible el proceso de enseñanza-aprendizaje de este alumnado supone otra gran barrera que los jóvenes identifican. Los participantes perciben grandes dificultades como la falta de información sobre servicios de apoyo, la desinformación en torno a la discapacidad visual, la escasa formación de los docentes para dar respuesta a sus necesidades especiales, el insuficiente dominio de herramientas TIC o tiflotecnología, la poca disposición para adaptar las metodologías didácticas o los materiales de trabajo por desconocimiento, o el excesivo uso de recursos visuales en el aula. Esta falta de información y de formación evidencia la necesaria re-profesionalización y actualización del profesorado para hacer real la cultura de la diversidad y de la inclusión que demandan muchos alumnos hoy en día, no solo aquellos con discapacidad visual.

Los participantes reconocen y valoran la labor que realizan las instituciones de apoyo especializado como la ONCE, tanto en su vida personal como en el propio centro educativo ordinario, como una palanca de cambio central para hacer de las aulas entornos inclusivos. Aprecian desde las primeras orientaciones que reciben tras recibir el diagnóstico y durante sus primeros años de vida hasta el apoyo técnico y el aprendizaje de cuestiones propias de la discapacidad visual como el aprendizaje del sistema braille. Este apoyo se extiende también al ámbito educativo, no solo a la orientación que brindan tanto a los centros escolares como a los docentes, sino también por la dotación de medios técnicos (máquinas Perkins, libros en braille...) y humanos (maestras especialistas de la ONCE que acompañan al alumno en el aula) que hacen posible el máximo nivel de bienestar y autonomía en entornos ordinarios de aprendizaje.

Sin embargo, pese a que ambos relatores valoran el esfuerzo de una determinada institución por la inclusión de las personas con discapacidad visual, los dos participantes inciden en que el principal facilitador del cambio reside en ellos mismos. Tras el "duelo" inicial de asumir una realidad que no se espera es fundamental mantener una actitud proactiva general que debe estar presente a lo largo de la vida. Reconocen que es un proceso de asimilación lento que debe realizar cada persona pero que la resiliencia es la única constante para crecer diferente en una sociedad que segrega y discrimina.

Me enfrento a una sociedad que discrimina y, además de discriminar, si tienes dos problemas, como que eres peor que el resto ya. Me he ganado muchos enemigos, profesores enemigos, alumnos enemigos, compañeros enemigos, porque hay mucha gente que no entiende que tú puedas ser diferente y hacer lo mismo que ellos. Mira, yo voy a hacer lo que a mí me apetezca, siempre he dicho, y ahora cuando creces más, que cada uno tiene que ser independiente, tiene que buscarse la vida y tiene que, sobre todo, sobre todo que afrontar las dificultades, no puedes aceptar todo lo que te dicen. ¿Por qué? Porque cuando aceptas que la gente te ponga límites, tú te pones limites aún más grandes. $Y$ en el momento en el que tú te pones límites cada vez más grandes no haces nada, estás en casa, tirao sin hacer nada. (Del libro "Creciendo diferente")

La gente es así porque la educación nos dice que lo importante es lo que ves, que lo importante es el ser igual que el resto y ser perfecto, cuanto más perfecto seas, mejor. Es una pena, pero somos así. La realidad no es la perfecta. La realidad es la que hay. $\Upsilon$ una persona porque fisicamente sea diferente no quiere decir que sea ni mejor ni 
peor, ni tan siquiera diferente, porque puedes pensar como la persona que tienes delante, pero ser diferente físicamente, nada más. (Del libro "La escuela oscura")

Los anteriores fragmentos son ejemplos ilustrativos del principal mensaje que ambos participantes quieren transmitir con su participación en la Biblioteca Humana: la importancia de asumir, convivir y respetar la propia discapacidad como palanca de cambio para que la sociedad en general y el sistema educativo en particular también lo haga. Su escolarización ha tenido lugar en contex tos educativos segregadores en los que los centros ordinarios y los docentes no solo no les han ofrecido oportunidades personales o académicas, sino que, además, en ellos han sufrido procesos de etiquetaje y estigmatización promovidos por una visión negativa de la diversidad. Pese a estas experiencias y a su temprana edad, los relatores asumen que si "los sitios los hacen inaccesibles las propias personas” deben ser esas mismas personas las que se conviertan en palancas de cambio.

\section{Conclusiones}

Los resultados del estudio, nos permiten plantear las siguientes cuestiones o ejes de reflexión: en relación al proceso de investigación desarrollado en este estudio, cabe plantear que el proceso seguido en el grupo HL ha supuesto para los participantes, el acceso a nuevas formas de aprendizaje que confirman la potencialidad de la construcción compartida y colaborativa del conocimiento y coinciden también con estudios previos (Nind, 2014) en señalar el poder transformador de la investigación inclusiva.

La formación de una personalidad activa e independiente exige una actitud personal positiva, en la que la autoestima y las emociones en general juegan un importante papel. Los casos que hemos visto así lo confirman. No obstante, si estos aspectos de la personalidad son importantes en todas las personas en desarrollo, en quienes presentan algún tipo de dificultad (sea esta físico, psicológica o social) adquieren un mayor protagonismo, dado que en las condiciones en las que se desenvuelve su vida se producen, con mayor facilidad, situaciones de no inclusión. Estas barreras a la inclusión en las personas con discapacidad visual pueden generar, como señalan Zorakhovich, Vladimirovna y Nikolaevna (2017), de forma especial, un sentido de "inferioridad".

En los dos relatos que en este trabajo se han analizado, la importancia de la ONCE como apoyo y guía, al asesorar y orientar al alumnado con discapacidad visual a lo largo de su formación escolar se muestra como un pilar básico para su desarrollo integral. No obstante, sería deseable que este apoyo de la ONCE siguiese fortaleciéndose en los años del bachillerato, no reduciéndose únicamente a los aspectos relacionados con lo académico, sino que también ayudase a fortalecer su personalidad. Resultados similares fueron los obtenidos por Abendaño y Díaz (2014) en una investigación realizada en Chile con cinco estudiantes universitarios con discapacidad visual: los padres y el centro de apoyo ocuparon un destacado lugar como facilitadores de su inclusión mientras que el profesorado y los pares del centro educativo se mostraron como barreras en el proceso. Por el contrario, en su caso Alnahdi (2019), constató que la familiaridad o el contacto con estudiantes con discapacidades fomentan actitudes positivas y un mayor grado de aceptación.

El proceso seguido ha permitido además la movilización y organización social a través de la HL mostrando el poder transformador, movilizador, de la investigación inclusiva y de las actuaciones conjuntas entre los participantes y la comunidad social. Crear vínculos de 
unión, compartiendo espacios y tiempos de forma real, es una buena fórmula para incrementar la familiaridad y disminuir estereotipos en las aulas, los centros y la vida social (Rosembaum, 2010). Como se ha visto, desafortunadamente y con demasiada frecuencia, el concepto de inclusión se limita a "introducir" alumnado con discapacidad en el aula, pero no va más allá. Dedicar tiempo a exponer las limitaciones y posibilidades de todo el alumnado abre la puerta para entender, comprender y convivir con las diferencias, sean estas del tipo que sean. En este estudio los jóvenes denuncian con firmeza que la diversidad no es sinónimo de discapacidad. La diversidad y la respuesta a la misma suponen una forma de ver las diferencias y actuar ante ellas que no puede reducirse a una mera cuestión de recursos o de una formación especializada. Es la mirada y el interés lo que condiciona los resultados finales. Cuando se piensa que incluir a estudiantes con discapacidad en el aula es aceptar un importante desafío cuya meta es alcanzar el éxito y se realizan todos los esfuerzos para que se convierta en una realidad, se camina sin duda hacia la plena inclusión (Banks y McCoy, 2017).

Durante mucho tiempo se pensó, y múltiples investigaciones así lo confirmaban (Metsiou, Papdopoulos y Agaliotis, 2011) que los y las estudiantes con discapacidad visual presentan dificultades en su comportamiento adaptativo total, entendido este como el desarrollo de las actividades diarias que se requieren para la suficiencia personal y social. No cabe duda de que las dificultades educativas se pueden patologizar fácilmente como dificultades inherentes a los estudiantes (Ainscow y Messiou, 2018). La realidad descrita en los relatos presentados en este trabajo pone el acento en otros aspectos que son, claramente, extrínsecos a ellos: la realidad de las aulas, con una administración preocupada porque todo ruede, que legisla pero que no modifica más allá del papel; con equipos directivos secuestrados por las tareas administrativas que cada vez son mayor en número y complejidad; con docentes con escasa o nula formación sobre discapacidad e inclusión y poco receptivos hacia una escuela que valora las diferencias; con alumnado que desconoce lo que las personas diferentes pueden aportarles y a los que nadie transmite una educación basada en valores que ponga en alza cambios de pensamiento y nuevas formas de actuar en el sistema educativo, en el día a día de los centros; y, por último, con un alumnado que presenta dificultades pero al que no se le da voz.

Este estudio coincide en señalar por tanto los problemas superpuestos, las culturas complejas y los desafíos que enfrentan los estudiantes con discapacidad visual, las escuelas y otros implicados en su proceso educativo. En cierto modo, y aquí radica la esperanza, todos estos obstáculos a la inclusión son potentes palancas de cambio si se busca la colaboración, si se conectan inclusión escolar y sociedad, y si estamos dispuestos a abrirnos a otras voces explorando sin cortapisas formas alternativas de trabajo (Ainscow y Messiou, 2018) y relación.

\section{Referencias}

Abendaño, C. y Díaz, Y. (2014). El proceso de integración educativa desde la perspectiva de cinco jóvenes universitarios con discapacidad visual de Concepción. Estudios Pedagógicos, 4O(2), 45-64. https://doi.org/10.4067/S07 18-07052014000300003

Ainscow, M. (2004). El desarrollo de sistemas educativos inclusivos: ¿Cuáles son las palancas de cambio? Journal of Educational Change, 5(4), 1-20. 
Ainscow, M. y Messiou, K. (2018). Engaging with the views of students to promote inclusion in education. Journal of Educational Change, 19(1), 1-17. https://doi.org/10.1007/s 10833-0179312-1

Alnahdi, G. H. (2019). Disabilities in schools: Children's attitudes towards peers with disabilities in Saudi Arabia. Research in Developmental Disabilities, 85, 1-7.

https://doi.org/10.1016/j.ridd.2018.10.004

Anyon, J. (2006) What count as educational research?: Notes towards a new paradigm. En G. Ladson-Billings y W. Tate (Eds.), Education research in the public interest: Social justice, action, and policy (pp. 17-26). Nueva York, NY: Teachers College Press.

Banks, J. y McCoy, S. (2017). An Irish solution? Questioning the expansion of special classes in an era of inclusive education. The Economic and Social Review, 48(4), 441-461.

Booth, T. (2011). The name of the rose: Inclusive values into action in teacher education. Prospects, 41, 303-318. https://doi.org/10.1007/s $11125-011-9200-z$

Booth, T. (1998). El sonido de las voces acalladas: Cuestiones acerca del uso de los métodos narrativos con personas con dificultades de aprendizaje. En L. Barton (Comp.), Discapacidad y sociedad (pp. 253-271). Madrid: Morata.

Booth, T. y Ainscow, M. (2011). Index for inclusion: Developing learning and participation in schools Bristol: Centre for Studies in Inclusive Education.

Metsiou, K., Papdopoulos, K. y Agaliotis, I. (2011). Adaptive behavior of primary school students with visual impairments: The impact of educational settings. Research in Developmental Disabilities, 32, 2340-2345. https://doi.org/10.1016/j.ridd.2011.07.030

Muñoz, M. L., López, M. y Assaél, J. (2015). Concepciones docentes para responder a la diversidad ¿Barreras o recursos para la inclusión educativa? Psicoperspectivas, 14(3), 68-79. https://doi.org/10.5027/psicoperspectivas-Vol 14-Issue3-fulltext-646

Nind, M. (2014). What is inclusive research? Londres: Bloomsbury.

Parrilla, A., Susinos, T., Gallego, C. y Martínez, B. (2017). Revisando críticamente cómo investigamos en educación inclusiva: Cuatro proyectos con un enfoque educativo y social. Revista Interuniversitaria de Formación del Profesorado, 89(2), 145-156.

Parrilla, A., Doval, M. I., Martínez, E., Muñoz, M. A., Raposo, M. y Zabalza, M. (octubre, 2011 ). Un mapa de preocupaciones y barreras sobre la educación inclusiva. Comunicación presentada en el I Congreso internacional de educación especial. Universidad de Cádiz.

Ravitch, S. (2014). The transformative power of taking and inquiry stance on practice: Practitioners research and narrative counter-narrative. Perspectives on Urban Education, $11(1), 5-10$.

Rip, A. (2016). The clothes of the emperor. An essay on RRI in and around Brussels. Journal of Responsible Innovation, 3(3), 290-304. https://doi.org/10.1080/23299460.2016.1255701

Senge, P. M. (1989). The fifth discipline: The art and practice of the learning organization. Londres: Century.

Sierra Martínez, S., Fiuza Asorey, M. y Parrilla, A. (2019). Nuevas herramientas metodológicas de investigación participativa: Las bibliotecas humanas. En B. Tejero Claver, O. Bernad Cavero y C. Lechuga Jiménez (Ed.), Investigando en contenidos de vanguardia (pp. 503-516). Madrid: Gedisa.

Walmsley, J. y Johnson, K. (2003). Inclusive research with people with learning disabilities: Past, present, and futures. Londres: Jessica Kingsley Publisher. 
Zorakhovich, V., Vladimirovna, G. y Nikolaevna, I. (2017). The impact of the institucional learning environments on the development of self-attitude in pupils with vision deficiency. Journal of Pharmaceutical Sciences and Research, 9(10), 1912-1917.

\section{Breve CV de las autoras}

\section{Silvia Sierra Martínez}

Doctora en Pedagogía (2017) por las Universidades de Vigo, Santiago de Compostela, Oviedo, Cantabria y A Coruña; y Licenciada en Psicopedagogía (2013) por la Universidad de Vigo. Inicia su formación docente e investigadora con una ayuda FPI en la mencionada Universidad. Actualmente es profesora en la Universidad de Vigo (categoría ayudante doctor) y colaboradora en la Universidad Internacional de La Rioja (UNIR). Ha participado en varios Proyectos del Plan Nacional de Investigación de I+D+i (Ministerio de Economía y Competitividad) y es miembro del Grupo de Investigación CÍES-UVigo. Su tesis doctoral y su producción científica tratan cuestiones relacionadas con la educación inclusiva, conformando sus principales líneas de investigación la investigación cualitativa, las metodologías de investigación participativas, las estrategias de recogida de información “amigas de los niños”, la voz del alumnado y las transiciones educativas. ORCID ID: https://orcid.org/oooo-0002-4367-3681. Email: sierra@uvigo.es

\section{María Fiuza Asorey}

Doctora en Psicología (Universidad de Santiago de Compostela) y Licenciada en Logopedia (Universidad de Lieja). Profesora contratada doctora en la Universidad de Santiago de Compostela (Facultad de Formación del Profesorado, Campus de Lugo). Coordinadora para el Campus de Lugo del Máster Universitario en Profesorado de Educación Secundaria Obligatoria y Bachillerato, Formación Profesional y Enseñanza de Idiomas para el Campus de Lugo desde 2013 a 2019. He participado en dos proyectos de investigación relacionados con la educación inclusiva (EDU2011-29928-Co3-01 y EDU2015-68617-C4-I-R) y publicado monografías, artículos y capítulos de libros en torno a mis líneas de investigación: dificultades de aprendizaje, educación inclusiva y trastornos de la voz. ORCID ID: https://orcid.org/OOOO-0003-4684-3188. Email: maria.fiuza@usc.es

\section{Ángeles Parrilla}

Ha mantenido en su trayectoria profesional un compromiso firme y sostenido con la educación inclusiva, así como con el desarrollo de una investigación educativa inclusiva y participativa. En los últimos 10 años ha dirigido 4 proyectos de investigación en el ámbito de los Procesos de Exclusión e Inclusión. En la actualidad es la coordinadora española de un proyecto internacional Erasmus KA Plus. Ha publicado en los últimos 10 años un importante número de artículos en revistas científicas indexadas nacionales e internacionales. Es directora y fundadora del Grupo de investigación CIES-UVigo. Es directora del Programa de Doctorado Interuniversitario en Equidad e innovación en Educación. Ha sido Visiting Research Fellow en la Universidad de Oxford (febrero-junio de 2019). ORCID ID: https://orcid.org/OOoO-0003-3393-6537. Email: parrilla@uvigo.es 